\title{
Abdominal aortic calcification score as a predictor of clinical outcome in peritoneal dialysis patients: a prospective cohort study
}

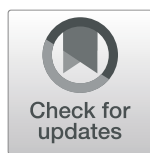

Dahua Ma ${ }^{1,2 \dagger}$, Hao Yan ${ }^{1,2 \dagger}$, Xiaoxiao Yang ${ }^{1,2}$, Zanzhe $\mathrm{Yu}^{1,2}$, Zhaohui $\mathrm{Ni}^{1,2}$ and Wei Fang ${ }^{1,2^{*}}$

\begin{abstract}
Background: Abdominal aortic calcification assessed by X-ray is recommended to evaluate vascular calcification in dialysis patients. It has been shown that abdominal aortic calcification score (AACS) is a predictor of adverse outcomes in hemodialysis patients, but evidence regarding its prognostic value in peritoneal dialysis (PD) patients is still insufficient. We aimed to examine the predictive role of AACS for major adverse cardiac and cerebrovascular events (MACCE) and mortality in PD patients.

Methods: Eligible patients undergoing PD between July 2011 and July 2014 were recruited. AACS was quantified using lateral lumbar radiography at recruitment. Patients were prospectively followed up until death, PD cessation, or to the end of the study (August 31, 2018). Both subdistribution hazards and cause-specific hazards models were used to evaluate the association between AACS and MACCE as well as mortality.
\end{abstract}

Results: 292 patients were enrolled, including 160 males (54.8\%) with mean age $57.1 \pm 15.2$ years and median PD duration 28.4 (IQR 12.0, 57.8) months. Among them, 75 (25.7\%) patients were comorbid with diabetes, and 94 (32.2\%) patients had cardiovascular disease (CVD). The average AACS was $2.0(0.0,6.0)$. Patients were categorized on the tertiles of AACS (Low AACS group, AACS $=0, n=125$; Medium AACS group, AACS 1-4, $n=72$; and High AACS group, AACS $>4, n=95)$. AACS was associated with age $(\mathrm{OR}=1.081, P<0.001)$, $\mathrm{PD}$ duration $(\mathrm{OR}=1.012, P=0.003)$, CVD $(O R=1.919, P=0.020)$ and diabetes $(O R=2.554, P=0.002)$. During the follow-up period of $43.6(24.6,50.7)$ months, there were 65 MACCEs and 84 deaths. Significantly higher cumulative incidences of all-cause mortality (Log-rank =35.992, $\mathrm{P}<0.001$; Gray $=38.662, \mathrm{P}<0.001)$ and MACCE (Log-rank = 26.146, $\mathrm{P}<0.001$; Gray $=27.810, \mathrm{P}<$ $0.001)$ were observed in the upper AACS tertile. AACS was an independent predictor of all-cause mortality $(H R=$ $2.438,95 \% \mathrm{Cl} 1.246-4.772, P=0.009 ; \mathrm{SHR}=2.323,95 \% \mathrm{Cl} 1.229-4.389, \mathrm{P}=0.009)$ and MACCE $(\mathrm{HR}=3.455,95 \% \mathrm{Cl}$ $1.734-6.884, P<0.001 ; \mathrm{SHR}=3.063,95 \% \mathrm{Cl} 1.460-6.430, P=0.003)$ in this study.

Conclusions: AACS was associated with age, PD duration, CVD and diabetes in PD patients. AACS could predict MACCE and all-cause mortality in this population. It thus might be a safe and feasible method to identify PD patients with adverse outcomes.

Keywords: Abdominal aortic calcification score, Major adverse cardiovascular and cerebrovascular events, All-cause mortality, Peritoneal dialysis

\footnotetext{
* Correspondence: fangwei_sh@126.com

†Dahua Ma and Hao Yan contributed equally to this work.

'Department of Nephrology, Renji Hospital, School of Medicine, Shanghai

Jiao Tong University, No. 160, Pujian Road, Pudong District, Shanghai 200127,

People's Republic of China

${ }^{2}$ Shanghai Center for Peritoneal Dialysis Research, Shanghai, China
}

(C) The Author(s). 2020 Open Access This article is licensed under a Creative Commons Attribution 4.0 International License, which permits use, sharing, adaptation, distribution and reproduction in any medium or format, as long as you give appropriate credit to the original author(s) and the source, provide a link to the Creative Commons licence, and indicate if changes were made. The images or other third party material in this article are included in the article's Creative Commons licence, unless indicated otherwise in a credit line to the material. If material is not included in the article's Creative Commons licence and your intended use is not permitted by statutory regulation or exceeds the permitted use, you will need to obtain permission directly from the copyright holder. To view a copy of this licence, visit http://creativecommons.org/licenses/by/4.0/ The Creative Commons Public Domain Dedication waiver (http://creativecommons.org/publicdomain/zero/1.0/) applies to the data made available in this article, unless otherwise stated in a credit line to the data. 


\section{Background}

Arterial calcification is associated with great risks of cardiovascular disease (CVD) among patients with different chronic kidney disease (CKD) stages, which translates into excess cardiovascular mortality in this population $[1,2]$. It has been well established that vascular calcification is more prevalent in CKD patients, especially those on dialysis, than that in the age-matched general population $[3,4]$. Several imaging techniques have been utilized in the evaluation of vascular calcification, such as ultrasonography, computed tomography (CT), mammograms and plain radiographs [5-7]. In dialysis patients, abdominal aortic calcification score (AACS) based on lateral lumbar X-Ray has been recommended to evaluate the extent of vascular calcification [8]. The AACS scale developed by Kauppila et al could independently predict all-cause mortality and nonfatal CVD events in hemodialysis (HD) pateints $[9,10]$, whereas there was limited clinical evidence to verify its prognostic value in patients undergoing peritoneal dialysis (PD).

Therefore, this study was conducted to explore the association of AACS with major adverse cardiovascular and cerebrovascular events (MACCE) and all-cause mortality in prevalent Chinese PD patients in a large university teaching hospital.

\section{Methods}

\section{Patients and study design}

This was a single-center, prospective, cohort study. Patients aged at least 18 years who had been on PD for more than 3 months between July 2011 and July 2014 were recruited. Exclusion criteria were as follows: (1) with active infections, malignancy or pregnancy at the time of recruitment; (2) hybrid HD and PD; (3) refusal to provide consent. Eligible PD patients were enrolled and AACS was quantified in all patients using lateral lumbar radiography at recruitment. The patients were followed up until death, switch to hemodialysis, kidney transplantation, dialysis-independent renal recovery, transfer to other centers, or until August 31, 2018. All the patients were dialyzed with lactate-buffered glucosebased PD solutions (Dianeal ${ }^{\circ}$, Baxter, China).

\section{Clinical data collection}

At the time of enrollment, participants' demographic characteristics, underlying end-stage renal disease (ESRD) cause, PD duration, comorbidity status, laboratory parameters, PD regimen, and concomitant medications were recorded. Diabetes mellitus was defined either as a comorbid condition or as the aetiology of ESRD. Hypertension was determined as blood pressure consistently higher than $140 / 90 \mathrm{mmHg}$ or have been on the treatment of hypertension medication. Pre-existing cardiovascular disease was defined as the history of any undermentioned condition: acute coronary syndrome, heart failure, cerebral infarction or hemorrhage, coronary artery atherosclerosis confirmed by percutaneous coronary intervention (PCI) or coronary artery bypass grafting (CABG) therapy.

Laboratory parameters including hemoglobin, highsensitivity $\mathrm{C}$ reaction protein (hs-CRP), serum albumin, lipid profiles, calcium, phosphate, intact parathyroid hormone (iPTH) and alkaline phosphatase (AKP) were evaluated. Adequacy of dialysis was estimated by measuring total weekly urea clearance $(\mathrm{Kt} / \mathrm{V})$ by standard methods [11]. Residual renal function was calculated as an average of 24-h urinary urea and creatinine clearance [12]. At the same time, baseline lateral lumbar X-Ray film was performed, and AACS was scored for each individual by two experienced radiologists who were blinded to the patients' clinical data using a specific scale previously described [6]. Patients were then divided into 3 groups according to AACS tertiles.

\section{Outcomes}

The primary outcome was all-cause mortality. The secondary outcome was the first MACCE during the follow-up. MACCE was defined as follows: fatal or nonfatal acute coronary syndrome (ACS), angina requiring coronary revascularization either by $\mathrm{PCI}$ or CABG, acute heart failure requiring hospitalization, sudden death, transient or permanent neurologic deficit with image evidence of cerebral ischemic/hemorrhagic lesion on computed tomography or magnetic resonance.

\section{Statistical analysis}

Continuous variables were reported as mean \pm standard deviation (SD) for normal distribution or median (interquartile range $[\mathrm{IQR}]$ ) for skewed distribution, and categorical variables as frequencies (percentages). Continuous variables were compared among groups by One-way ANOVA analysis or Kruskal-Wallis test, and categorical variables by Chi-square $(\mathrm{x} 2)$ test. Associated factors of abdominal aortic calcification were examined using a stepwise multivariable logistic model, and variables with a $p$ value $<0.1$ were included in the model except those with multicollinearity.

Considering the presence of competing events in this study, we additionally performed survival analysis by reporting subdistribution hazards attached to cumulative incidence [13]. For univariate analysis, both KaplanMeier and cumulative incidence competing risk (CICR) methods were used to estimate the probabilities of mortality and MACCE, and differences among groups were compared by the Log-rank test and Gray test respectively. For Multivariate analysis, cause-specific hazards and subdistribution hazards models were used to explore relative risks of all-cause mortality and MACCE for 
different variables. When the event of interest was allcause mortality, the competing events included switch to $\mathrm{HD}$, receiving kidney transplant and transfer to other centers. When the event of interest was MACCE occurrence, the competing events included switch to HD, receiving kidney transplant, transfer to other centers and death unrelated to MACCE.

Data analysis was performed using SPSS for windows version 25 (IBM Corporation, Armonk, NY) and R for windows vision 3.6.1. All probabilities were two-tailed, and $P$-value $<0.05$ was considered statistically significant.

\section{Results}

\section{Patient characteristics and associated factors of AACS}

The cohort consisted of 292 PD patients, among whom $160(54.8 \%)$ were males. The mean age was $57.1 \pm 15.2$ years, and the median PD duration was $28.4(12.0,57.8)$ months. Among them, 75 (25.7\%) patients had diabetes and $94(32.2 \%)$ had pre-existing cardiovascular disease. The demographic characteristics, ESRD etiologies, comorbidity status, and baseline laboratory parameters were summarized in Table 1. A history of cardiovascular or cerebrovascular disease before enrollment was identified in 94 (32.2\%) patients, including ischemic stroke $(n=30)$, hemorrhagic stroke $(n=7)$, subarachnoid hemorrhage $(n=1)$, myocardial infarction $(n=7)$, congestive heart failure $(n=49)$, ischemic heart disease requiring CABG $(n=2)$, and angina $(n=19)$. Some patients $(\mathrm{n}=4)$ had had multiple CVD strikes.

Abdominal artery calcification was observed in 167 (57.2\%) participants according to the results of lateral lumbar X-ray film. The median AACS of the entire cohort was $2.0(0.0,6.0)$. Patients were divided into 3 groups according to the tertiles of AACS: Low AACS group, $\mathrm{AACS}=0, n=125$; Medium AACS group, AACS $1-4, n=72$; and High AACS group, AACS $>4, n=95$.

Participants with high AACS were more likely to be older, with higher BMI and a longer PD duration, more prevalent in hypertension, diabetes, and CVD, with lower serum albumin and HDL, but greater hs-CRP and TG (Table 1). Multivariate linear regression revealed that older age (OR 1.081, 95\% CI 1.056-1.107, $P<$ 0.001), longer PD duration (OR 1.012, 95\% CI 1.004$1.019, P=0.003$ ), presence of diabetes (OR $2.554,95 \% \mathrm{CI}$ 1.415-4.609, $P=0.002$ ) and previous CVD (OR 1.919, 95\% CI 1.108-3.325, $P=0.020)$ were associated with high AACS (Table 2).

\section{Association between AACS and all-cause mortality}

After the median follow-up of $43.6(24.6,50.7)$ months, 84 (28.8\%) patients had died, $42(14.4 \%)$ had been switched to hemodialysis, 22 (7.5\%) had received kidney transplantation, and $11(3.8 \%)$ had transferred to other centers.

A total of 50 patients (59.52\%) died because of a lethal MACCE strike, which was the leading cause of death, including 28 cases of sudden death, 7 of acute myocardial infarction, 7 of cerebral hemorrhage, 6 of cerebral infarction, and 2 of decompensated heart failure. Infection was the second mortality cause $(n=23)$, including peritonitis in 9 patients. The other deceased died from gastrointestinal bleeding $(n=5)$, malignancy $(n=1)$, or unknown causes $(\mathrm{n}=5)$. AACS was greater in the dead than that in the survivors $[5.0(1.0,9.0)$ vs. $0.0(0.0,4.0), P<0.001]$.

The estimated cumulative mortality incidences were significantly lower in patients of Low AACS group than in their counterparts of Medium and High AACS group (Log-rank $=35.992, P<0.001$, Fig.1a; Gray $=38.662, P<$ 0.001, Fig.1b). The multivariate Cox regression model showed that the baseline AACS independently predicted all-cause mortality (Medium AACS group vs. Low AACS group: HR 2.028, 95\% CI 1.014-4.057, $P=0.046$; High AACS group vs. Low AACS group: HR 2.438, 95\% CI 1.246-4.772, $P=0.009$ ) after adjusting for age, gender, $\mathrm{BMI}$, hypertension, diabetes, previous CVD, PD duration, total $\mathrm{Kt} / \mathrm{V}$, serum albumin, $\mathrm{TG}$, and use of calcium-based phosphate binders (Table 3). In the presence of competing events including switch to HD, receiving kidney transplant and transfer to other centers, severe abdominal artery calcification remained independently predictable of all-cause mortality (Medium AACS group vs. Low AACS group: SHR 1.772, 95\% CI 0.899-3.496, $P=0.099$; High AACS group vs. Low AACS group: SHR 2.323, 95\%CI 1.229-4.389, $P=0.009$; Table 4).

\section{The association between AACS and MACCE}

MACCE occurred in $65(22.3 \%)$ patients during the follow-up, including ACS $(n=14)$, acute left ventricular failure $(n=3)$, cerebral infarction $(n=14)$, cerebral hemorrhage $(n=10)$, and sudden cardiac deaths $(n=$ 24). Patients who developed MACCE showed higher AACS than the others did $[4.5(1.0,8.0)$ vs. $1.0(0.0$, 5.0), $p<0.001$.

Patients of the Low AACS group had significantly lower cumulative incidences of MACCE (Log-rank= 26.146, $P<0.001 ; \quad$ Fig.2a; Gray $=27.810, \quad P<0.001$, Fig.2b). After adjusting for age, gender, BMI, hypertension, diabetes, previous CVD, PD duration, total $\mathrm{Kt} / \mathrm{V}$, serum albumin, and LDL-c, multivariate Cox regression analysis presented the baseline AACS as an independent predictor of MACCE (Medium AACS group vs. Low AACS group: HR 2.976, 95\% CI $1.420-6.238, P=0.004$; High AACS group vs. Low AACS group: HR 3.455, 95\% CI 1.734-6.881, $P<$ 
Table 1 Clinical characteristics of patients across tertiles of AACS

\begin{tabular}{|c|c|c|c|c|c|}
\hline & $\begin{array}{l}\text { Total } \\
(n=292)\end{array}$ & $\begin{array}{l}\text { Low AACS group } \\
(n=125)\end{array}$ & $\begin{array}{l}\text { Medium AACS group } \\
(n=72)\end{array}$ & $\begin{array}{l}\text { High AACS group } \\
(n=95)\end{array}$ & $P$ Value \\
\hline Age (year) & $57.1 \pm 15.2$ & $48.5 \pm 14.9$ & $59.8 \pm 12.1$ & $66.4 \pm 10.8$ & $<0.001$ \\
\hline Male gender, n (\%) & $160(54.8)$ & $67(46.4)$ & $37(51.4)$ & $56(58.9)$ & 0.586 \\
\hline BMI $\left(\mathrm{kg} / \mathrm{m}^{2}\right)$ & $22.4(20.3,25.0)$ & $21.6(19.7,24.5)$ & $22.5(21.0,25.5)$ & $23.1(21.4,25.5)$ & 0.013 \\
\hline Dialysis Duration (month) & $28.4(12.0,57.8)$ & $21.7(7.6,52.7)$ & $29.2(13.6,56.9)$ & $41.7(19.0,71.0)$ & 0.004 \\
\hline CKD etiology, n (\%) & & & & & 0.105 \\
\hline Glomerulonephritis & $103(35.3 \%)$ & $51(40.8 \%)$ & $24(33.3 \%)$ & $28(29.5 \%)$ & \\
\hline Polycystic kidney & $9(3.1 \%)$ & $5(4.0 \%)$ & $3(4.2 \%)$ & $1(1.1 \%)$ & \\
\hline Diabetic nephropathy & $43(14.7 \%)$ & $7(5.6)$ & $15(20.8)$ & $21(22.1)$ & \\
\hline Hypertension & $12(4.1 \%)$ & $5(4.0 \%)$ & $3(4.2 \%)$ & $4(4.2 \%)$ & \\
\hline Others & $10(3.4 \%)$ & $5(4.0 \%)$ & $1(1.4 \%)$ & $4(4.2 \%)$ & \\
\hline Unknown & 115(39.4\%) & $52(41.6 \%)$ & $26(36.1 \%)$ & $37(38.9 \%)$ & \\
\hline Hypertension, n (\%) & $270(92.5 \%)$ & $110(88.0 \%)$ & 69 (95.8\%) & $91(95.8 \%)$ & 0.044 \\
\hline Diabetes, n (\%) & 75 (25.7\%) & $13(10.4 \%)$ & $24(33.3 \%)$ & $38(50.7 \%)$ & $<0.001$ \\
\hline CVD history, n (\%) & $94(32.2 \%)$ & $20(16.0 \%)$ & $28(38.9 \%)$ & $46(48.9 \%)$ & $<0.001$ \\
\hline Total Kt/N & $1.82(1.61,2.11)$ & $1.84(1.63,2.18)$ & $1.82(1.65,2.05)$ & $1.81(1.58,2.07)$ & 0.292 \\
\hline $\operatorname{RRF}(\mathrm{ml} / \mathrm{min})$ & $0.9(0.0,2.9)$ & $1.0(0.0,3.7)$ & $0.7(0.0,2.7)$ & $0.8(0.0,2.0)$ & 0.204 \\
\hline Urine volume $(\mathrm{ml} / \mathrm{d})$ & $300(0,800)$ & $375(0,988)$ & $300(0,725)$ & $280(0,600)$ & 0.167 \\
\hline Albumin (g/L) & $37.4(34.6,40.5)$ & $38.6(35.4,41.5)$ & $37.8(34.3,40.4)$ & $37.2(33.2,39.7)$ & 0.031 \\
\hline hs-CRP (mg/L) & $2.3(0.7,5.8)$ & $1.4(0.6,4.5)$ & $2.9(1.0,6.5)$ & $3.4(1.2,7.6)$ & 0.002 \\
\hline Corrected calcium (mmol/L) & $2.35 \pm 0.20$ & $2.32 \pm 0.18$ & $2.37 \pm 0.21$ & $2.37 \pm 0.21$ & 0.137 \\
\hline Phosphorus (mmol/L) & $1.54(1.26,1.84)$ & $1.52(1.28,1.87)$ & $1.47(1.21,1.77)$ & $1.60(1.25,1.85)$ & 0.789 \\
\hline iPTH (pg/ml) & $274(126,568)$ & $323(131,595)$ & $300(99,527)$ & $242(130,531)$ & 0.659 \\
\hline AKP $(U / L)$ & $85.0(65.0,113.0)$ & $86.5(65.0,109.8)$ & $80.0(64.0,104.8)$ & $89.0(66.0,126.0)$ & 0.221 \\
\hline TG $(\mathrm{mmol} / \mathrm{L})$ & $1.82(1.23,2.79)$ & $1.65(1.14,2.30)$ & $1.93(1.24,2.41)$ & $2.21(1.36,3.26)$ & 0.007 \\
\hline TC (mmol/L) & $5.08 \pm 1.19$ & $4.99 \pm 1.11$ & $5.02 \pm 1.09$ & $5.22 \pm 1.35$ & 0.346 \\
\hline LDL (mmol/L) & $2.86(2.18,3.51)$ & $2.68(2.18,3.62)$ & $2.98(2.06,3.58)$ & $2.96(2.21,3.38)$ & 0.963 \\
\hline $\mathrm{HDL}(\mathrm{mmol} / \mathrm{L})$ & $1.11(0.90,1.46)$ & $1.21(0.95,1.51)$ & $1.11(0.90,1.40)$ & $1.00(0.86,1.39)$ & 0.002 \\
\hline Use of calcium-based phosphate binder, n (\%) & $210(72.2 \%)$ & $94(75.2 \%)$ & $46(64.8 \%)$ & $70(73.7 \%)$ & 0.272 \\
\hline Use of Low-calcium dialysate, n (\%) & $114(39.2 \%)$ & $48(38.4 \%)$ & $24(33.8 \%)$ & $42(44.2 \%)$ & 0.386 \\
\hline
\end{tabular}

Abbreviations: AACS abdominal aortic calcification score, $B M I$ body mass index, CVD cardiovascular disease, $R R F$ residual renal function, hs-CRP: high-sensitivity $C$ reaction protein, $T C$ total cholesterol, TG total triglyceride, $H D L$ high-density lipoprotein, $L D L$ low- density lipoprotein, Corrected calcium: serum total calcium (corrected by albumin), iPTH intact-parathyroid hormone, AKP alkaline phosphatase. Calcium-based phosphate binder refers to Calcium Carbonate and Calcium Acetate

0.001; Table 5). Further adjusted by competing events including switch to HD, receiving kidney transplant, transfer to other centers and death unrelated to MACCE, AACS remained as an independent predictor of MACCE (Medium AACS group vs. Low AACS group: SHR 2.823, 95\% CI 1.333-5.970, $P=0.007$; High AACS group vs. Low AACS group: SHR 3.063, 95\%CI 1.460-6.430, $P=0.003$; Table 6).

\section{Discussion}

This prospective study showed that abdominal artery calcification was common in PD patients. Older age, longer PD duration, diabetes, and previous CVD were correlated with AACS in prevalent PD patients. Furthermore, high AACS was an independent predictor of subsequent cardio-cerebral vascular disease and all-cause mortality in the study cohort.

Abdominal artery calcification is particularly common in dialysis patients, with the overall prevalence ranging from one third to more than $80 \%[4,14-16]$. We reported an abdominal artery calcification prevalence of $57.2 \%$ in our PD patients, in correspondence with published meta results in Asia population [4]. There were a few cross-sectional studies suggesting that abdominal artery calcification might be less common in PD patients compared to HD patients [14], 
Table 2 Potential risk factors of greater AACS in the study participants

\begin{tabular}{llll}
\hline & $\beta$ & OR $(95 \% \mathrm{Cl})$ & $P$ Value \\
\hline Age (year) & 0.078 & $1.081(1.057,1.106)$ & $<0.001$ \\
Male gender & 0.141 & $1.152(0.699,1.897)$ & 0.579 \\
BMI (kg/m²) & -0.011 & $0.989(0.927,1.055)$ & 0.730 \\
Dialysis Duration (month) & 0.012 & $1.012(1.004,1.019)$ & 0.003 \\
Hypertension & 0.385 & $1.469(0.527,4.098)$ & 0.462 \\
Diabetes & 0.938 & $2.554(1.415,4.609)$ & 0.002 \\
CVD history & 0.652 & $1.919(1.108,3.325)$ & 0.020 \\
Albumin (g/L) & 0.027 & $1.027(0.968,1.089)$ & 0.376 \\
hs-CRP (mg/L) & 0.015 & $1.015(0.987,1.043)$ & 0.295 \\
RRF (ml/min) & -0.104 & $0.901(0.796,1.021)$ & 0.101 \\
\hline
\end{tabular}

Abbreviations: BMI body mass index, CVD cardiovascular disease, $h s$-CRP highsensitivity $C$ reaction protein, $R R F$ residual renal function, $O R$ odds ratio

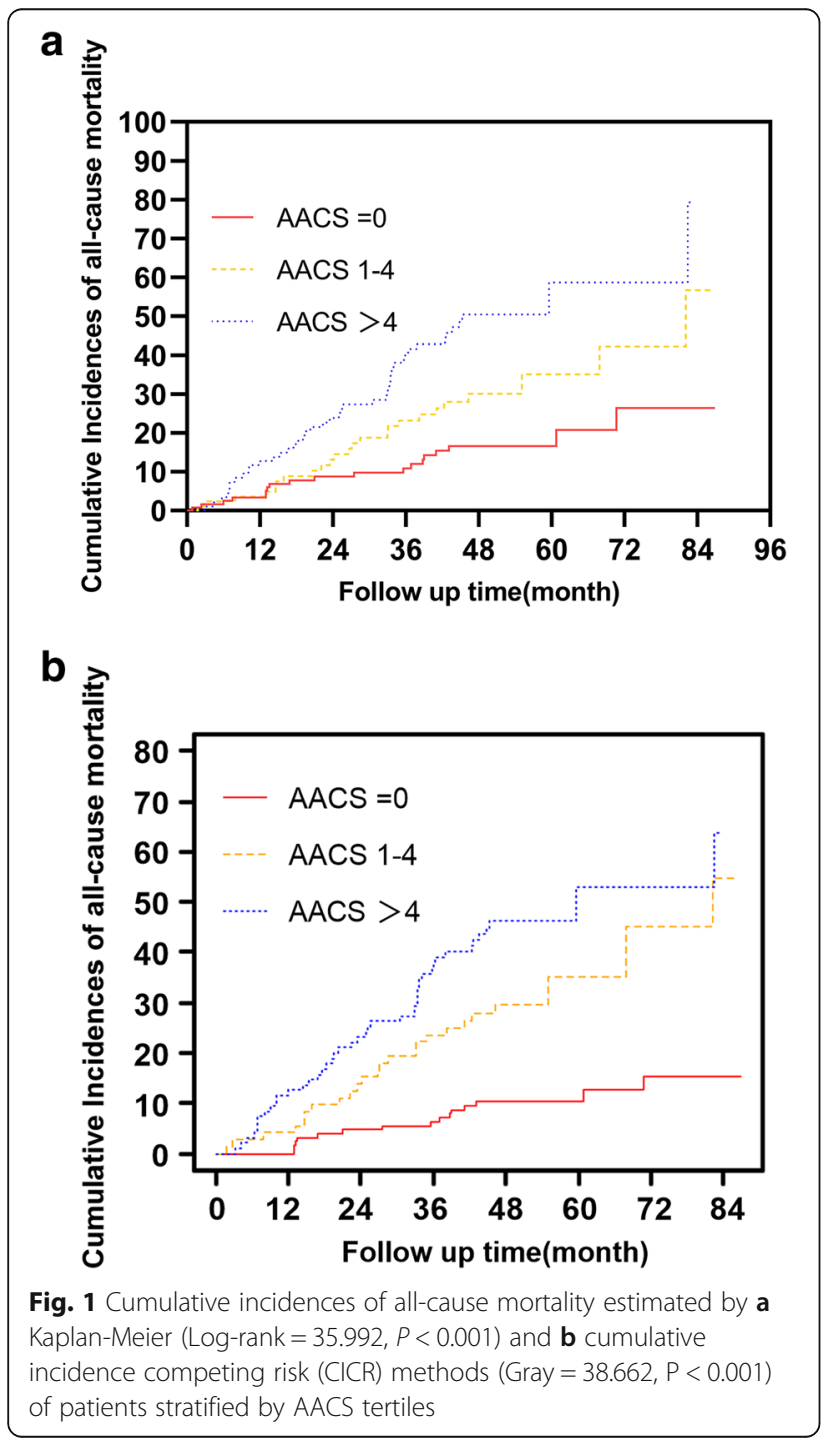

while other studies reported no advantage of one modality over the other $[4,17]$.

Vascular calcification is a sophisticated process and our results suggest both demographics and comorbidity might contribute to its development. Age is a traditional risk factor for vascular calcification [16, 18, 19]. With body aging, pathologies promoting calcium deposits such as lipid deposition and decrement of smooth muscle and elastin might occur in vessel walls $[18,20]$. Prolonged exposure to uremic toxins and biocompatible dialysate could lead to sustained activation of calcification inducers along with the down-regulation of calcification inhibitors $[21,22]$. It has been shown that the prevalence of vascular calcification in incident PD patients increases from 47 to $56 \%$ after 1 year on dialysis [23]. Diabetes closely associated with vascular calcification, and insulin resistance, oxidative stress, and hyperglycemia are possible mechanisms participating in [24, 25]. In consist with several other studies, a previous history of CVD was found to be associated with higher AACS [16, 19]. No relationship was found between phosphate, PTH and calcium and abdominal artery calcification in the present study, which were reported as accelerators of calcification in some observational studies $[26,27]$. The lack of association may relate to the time-dependent high variability of these biochemical makers since our analysis only included the parameters measured at the enrollment.

Imaging examinations to investigate vascular calcification include CT scan, abdominal plain X-ray, mammography and vascular ultrasound [5-7]. The optimum diagnostic technique for vascular calcification remains unsettled. CT based imaging is outstanding in accuracy and reproducibility, yet plain radiography is a convenient and inexpensive alternative, and it delivers substantially lower radiation [28]. The predictive value of AACS based on lateral lumbar X-ray film for CVD and mortality has been validated in the general population $[29,30]$. Moreover, it has been shown that AACS correlates with coronary artery calcification score by electron beam CT in HD population [31].

Previous studies had provided evidence of abdominal artery calcification as a prognostic factor in ESRD patients. The Calcification Outcome in Renal Disease (CORD) Study, a large prospective study conducted in 47 European dialysis centers, explored the relationship between AACS and all-cause mortality as well as nonfatal cardiovascular events in a cohort of 1084 dialysis patients, of which the vast majority were on HD. The investigators found AACS to be an independent predictor of the adverse outcomes [9]. A few studies focused on PD populations and found that abdominal artery calcification is a risk factor of both mortality and CVD occurrence, but were carried in a rather small 
Table 3 Cause-specific hazards model of different variables on all-cause mortality

\begin{tabular}{|c|c|c|c|c|}
\hline \multirow[t]{2}{*}{ Variable } & \multicolumn{2}{|l|}{ Univariate Analysis } & \multicolumn{2}{|l|}{ Multivariate Analysis } \\
\hline & $\mathrm{HR}(95 \% \mathrm{Cl})$ & $P$ Value & HR $(95 \% \mathrm{Cl})$ & $P$ Value \\
\hline Age (year) & $1.054(1.036,1.037)$ & $<0.001$ & $1.035(1.012,1.058)$ & 0.002 \\
\hline Male Gender & $0.920(0.605,1.398)$ & 0.695 & - & - \\
\hline Diabetes & $2.500(1.631,3.831)$ & $<0.001$ & - & - \\
\hline Dialysis Duration (month) & $0.996(0.990,1.002)$ & 0.226 & - & - \\
\hline Hypertension & $4.657(1.140,19.025)$ & 0.032 & - & - \\
\hline CVD history & $3.499(2.287,5.353)$ & $<0.001$ & $2.146(1.351,3.407)$ & 0.001 \\
\hline BMI $\left(\mathrm{kg} / \mathrm{m}^{2}\right)$ & $1.050(0.997,1.107)$ & 0.067 & - & - \\
\hline Albumin(g/L) & $0.905(0.866,0.946)$ & $<0.001$ & $0.932(0.882,0.984)$ & 0.012 \\
\hline $\mathrm{Kt} / \mathrm{N}$ & $0.482(0.263,0.884)$ & 0.018 & - & - \\
\hline TG (mmol/L) & $1.115(1.011,1.230)$ & 0.030 & $1.131(1.014,1.261)$ & 0.027 \\
\hline Calcium-based phosphate binders & $0.676(0.437,1.043)$ & 0.077 & - & - \\
\hline Medium vs. Low AACS group & $3.374(1.764,6.452)$ & $<0.001$ & $2.028(1.014,4.057)$ & 0.046 \\
\hline High vs. Low AACS group & $5.200(2.886,9.369)$ & $<0.001$ & $2.438(1.246,4.772)$ & 0.009 \\
\hline
\end{tabular}

Abbreviations: CVD cardiovascular disease, $B M I$ body mass index, $T G$ total triglyceride, $H R$ hazard ratio. Calcium-based phosphate binder refers to Calcium Carbonate and Calcium Acetate

population or with restricted age-bracket [32, 33]. This relatively larger cohort study with longer follow-up periods might help for the extrapolation of these findings in PD population. Recently, Mäkelä $S$ et al. reported that severe arterial calcification $(\mathrm{AACS} \geq 7)$ rather than moderate calcification $(1 \leq \mathrm{AACS}<7)$ was associated with adverse outcomes in Finnish PD patients [34]. Comparatively, out study found that even mild calcification $(\mathrm{AACS} \leq 4)$ can double the risk of MACCE and death compared to the ones without abdominal artery calcification, and regular screening of abdominal artery calcification to identify PD patients with excess CVD risks are therefore suggested.

Therapeutic interventions to prevent the progression of vascular calcification may be of great value in these patients identified with high AACS, which requires the long-term implementation of systematic interventions targeting at multiple pathogenic components $[8$,

Table 4 Subdistribution hazards model of different variables on all-cause mortality

\begin{tabular}{|c|c|c|c|c|}
\hline \multirow[t]{2}{*}{ Variable } & \multicolumn{2}{|l|}{ Univariate Analysis } & \multicolumn{2}{|l|}{ Multivariate Analysis } \\
\hline & SHR $(95 \% \mathrm{Cl})$ & $P$ Value & SHR $(95 \% \mathrm{Cl})$ & $P$ Value \\
\hline Age (year) & $1.060(1.040,1.080)$ & $<0.001$ & $1.040(1.012,1.068)$ & 0.004 \\
\hline Male Gender & $0.927(0.605,1.420)$ & 0.730 & - & - \\
\hline Diabetes & $2.650(1.720,4.080)$ & $<0.001$ & - & - \\
\hline Dialysis Duration (month) & $0.997(0.992,1.000)$ & 0.350 & - & - \\
\hline Hypertension & $8.120(1.10,60.200)$ & 0.040 & - & - \\
\hline CVD history & $3.380(2.200,5.190)$ & $<0.001$ & - & - \\
\hline BMI (kg/m2) & $1.040(0.987,1.100)$ & 0.130 & - & - \\
\hline Albumin (g/L) & $0.905(0.856,0.947)$ & $<0.001$ & $0.946(0.896,0.999)$ & 0.046 \\
\hline hs-CRP (mg/L) & $1.010(1.000,1.020)$ & 0.003 & - & - \\
\hline $\mathrm{Kt} / \mathrm{N}$ & $0.519(0.265,1.020)$ & 0.056 & - & - \\
\hline TG $(\mathrm{mmol} / \mathrm{L})$ & $1.090(0.999,1.200)$ & 0.052 & - & - \\
\hline Calcium-based phosphate binders & $0.600(0.387,0.931)$ & 0.023 & - & - \\
\hline Medium vs. Low AACS group & $3.350(1.770,6.350)$ & $<0.001$ & $1.772(0.899,3.496)$ & 0.099 \\
\hline High vs. Low AACS group & $5.460(3.050,9.780)$ & $<0.001$ & $2.323(1.229,4.389)$ & 0.009 \\
\hline
\end{tabular}




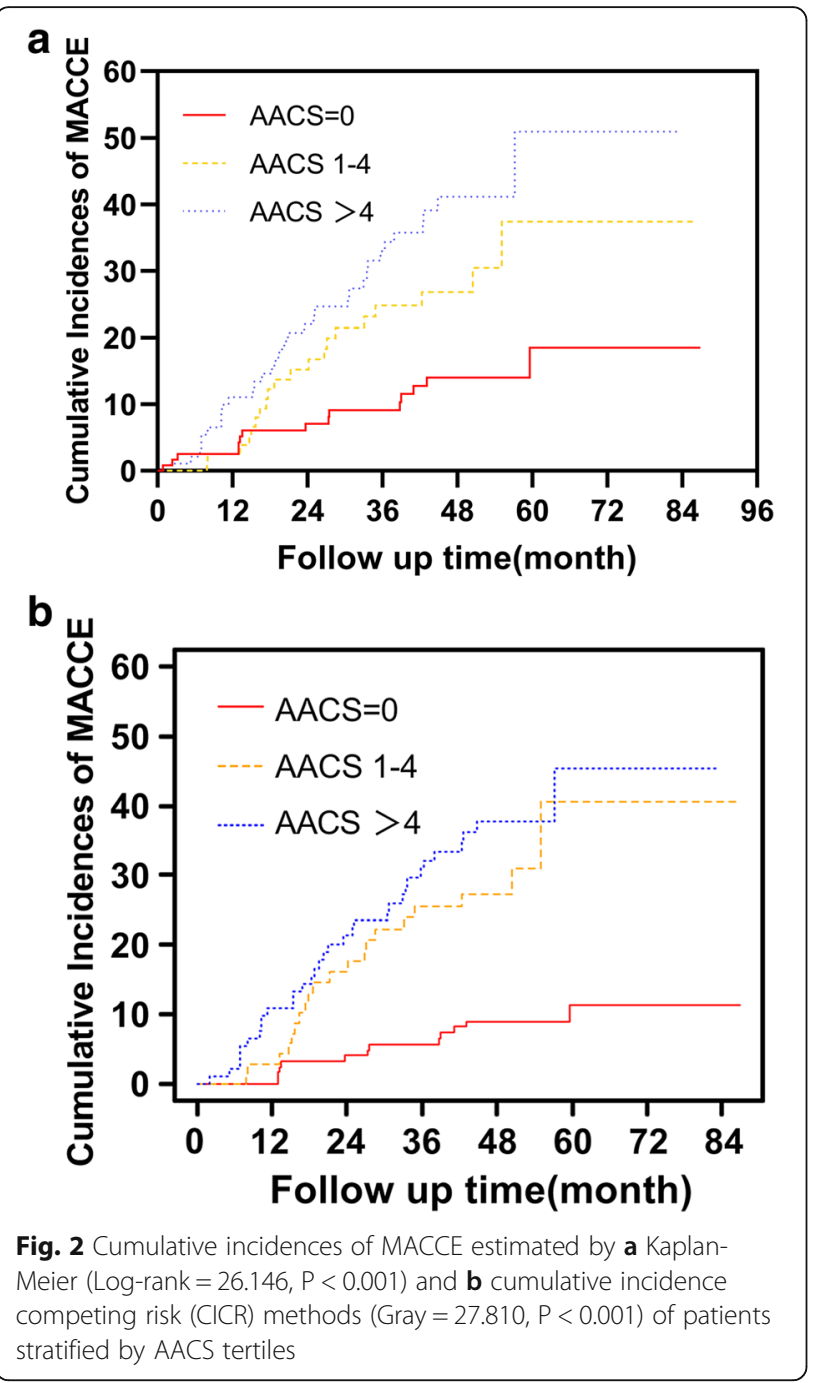

35]. Control of mineral metabolism was considered critical to reducing the vascular calcification progression, and non-calcium-based phosphate binders and/ or $1.25 \mathrm{mmol} / \mathrm{L}$ calcium dialysate are suggested. Compared with $1.75 \mathrm{mmol} / \mathrm{L}$ calcium dialysate, utilization of $1.25 \mathrm{mmol} / \mathrm{L}$ calcium dialysate tended to decrease serum calcium level without inducing high turn-over bone lesion in PD patients [36, 37]. A meta-analysis reported that in CKD stage 3-5D patients, Agatston scores were significantly lower in patients treated with non-calcium-based phosphate binders than those on calcium-based binders, with a mean score difference of -95.26 (95\%CI -146.68 to -43.84$)$ [38]. Excessive use of activated vitamin D should be avoided in patients with severe vascular calcification, and parathyroidectomy is recommended for severe secondary hyperparathyroidism [35]. Limited evidence implied that no beneficial effect of cinacalcet treatment on arterial stiffness despite the remarkable lowering of the PTH level in PD patients [39, 40], and clearly further randomized controlled trials with better design are needed.

CVD is highly prevalent in ESRD patients and is the leading cause of death in dialysis patients that accounts for more than $50 \%$ of all-cause mortality [9]. The presence and extent of arterial calcification are regarded as one of the major determinants for CVD morbidity and mortality through multifaceted pathogenesis. In CKD population, arterial calcification is characterized by lesions that occur in the medial vascular wall, which exacerbates arterial stiffness termed as arteriosclerosis [41]. Arterial rigidity is measurable through pulse wave velocity (PWV). Numerous studies in CKD and ESRD patients have reported this

Table 5 Cause-specific hazards model of different variables on MACCE

\begin{tabular}{|c|c|c|c|c|}
\hline & \multicolumn{2}{|l|}{ Univariate Analysis } & \multicolumn{2}{|c|}{ Multivariate Analysis } \\
\hline & HR $(95 \% \mathrm{Cl})$ & $P$ value & $\mathrm{HR}(95 \% \mathrm{Cl})$ & $P$ Value \\
\hline Age (year) & $1.041(1.021,1.061)$ & $<0.001$ & $1.011(0.986,1.035)$ & 0.396 \\
\hline Male Gender & $1.183(0.722,1.938)$ & 0.504 & - & - \\
\hline Dialysis Duration (month) & $0.993(0.985,1.000)$ & 0.067 & - & - \\
\hline Diabetes & $2.328(1.419,3.819)$ & 0.001 & - & - \\
\hline Hypertension & $2.176(0.777,12.991)$ & 0.108 & - & - \\
\hline CVD history & $2.677(1.647,4.352)$ & $<0.001$ & $2.221(1.324,3.726)$ & 0.003 \\
\hline $\mathrm{BMI}\left(\mathrm{kg} / \mathrm{m}^{2}\right)$ & $1.065(1.004,1.129)$ & 0.035 & - & - \\
\hline Albumin(g/L) & $0.932(0.885,0.981)$ & 0.007 & - & - \\
\hline Total Kt/N & $0.528(0.259,1.074)$ & 0.078 & - & - \\
\hline $\mathrm{LDL}(\mathrm{mmol} / \mathrm{L})$ & $1.276(1.083,1.504)$ & 0.004 & $1.269(1.056,1.525)$ & 0.011 \\
\hline Medium vs. Low AACS group & $4.830(2.493,9.436)$ & $<0.001$ & $2.976(1.420,6.238)$ & 0.004 \\
\hline High vs. Low AACS group & $3.799(1.845,7.824)$ & $<0.001$ & $3.455(1.734,6.884)$ & 0.000 \\
\hline
\end{tabular}


Table 6 Subdistribution hazards model of different variables on MACCE

\begin{tabular}{|c|c|c|c|c|}
\hline & \multicolumn{2}{|l|}{ Univariate Analysis } & \multicolumn{2}{|l|}{ Multivariate Analysis } \\
\hline & SHR $(95 \% \mathrm{Cl})$ & $P$ Value & SHR $(95 \% \mathrm{Cl})$ & $P$ Value \\
\hline Age (year) & $1.040(1.020,1.060)$ & $<0.001$ & - & - \\
\hline Male Gender & $1.140(0.698,1.870)$ & 0.600 & - & - \\
\hline Dialysis Duration (month) & $0.994(0.987,1.000)$ & 0.070 & - & - \\
\hline Diabetes & $2.390(1.450,3.910)$ & $<0.001$ & - & - \\
\hline Hypertension & $3.050(0.763,12.200)$ & 0.110 & - & - \\
\hline CVD history & $2.840(1.750,4.630)$ & $<0.001$ & $1.790(1.024,3.130)$ & 0.041 \\
\hline $\mathrm{BMI}\left(\mathrm{kg} / \mathrm{m}^{2}\right)$ & $1.060(1.010,1.130)$ & 0.026 & - & - \\
\hline Albumin(g/L) & $0.930(0.884,0.979)$ & 0.005 & - & - \\
\hline hs-CRP (mg/L) & $1.010(1.000,1.020)$ & 0.022 & - & - \\
\hline $\mathrm{LDL}(\mathrm{mmol} / \mathrm{L})$ & $1.320(1.070,1.640)$ & 0.011 & $1.330(1.080,1.640)$ & 0.007 \\
\hline Medium vs. Low AACS group & $3.710(1.820,7.570)$ & $<0.001$ & $2.823(1.333,5.970)$ & 0.007 \\
\hline High vs. Low AACS group & $5.000(2.590,9.640)$ & $<0.001$ & $3.063(1.460,6.430)$ & 0.003 \\
\hline
\end{tabular}

Abbreviations: CVD cardiovascular disease, $B M I$ body mass index, $h s-C R P$ high-sensitivity $C$ reaction protein, $L D L$ low- density lipoprotein, $S H R$ subdistribution hazard ratio

positive correlation between increased arterial calcification and faster PWV [42]. It is responsible for escalated systolic blood pressure, decreased diastolic blood pressure, and widened pulsatile pressure [43]. Increased wave reflections and high pulse pressure are independent risk factors for mortality [44]. Elevated systolic pressure aggravates ventricle afterload and oxygen consumption, leads to left ventricular hypertrophy, and results in myocardial fibrosis, arrhythmias and congestive heart failure' [45]. $1 \mathrm{~g} / \mathrm{m}^{2.7} /$ month increase in left ventricular mass index was associated with a $62 \%$ increase in the incident risk of cardiovascular events in HD patients [46]. Decreased diastolic pressure limits coronary perfusion and promotes myocardial ischemia, which in turn urges myocardial infarction and lethal arrhythmias [47].

Coronary artery calcification (CAC) is the traditional marker for coronary atherosclerotic burden and direct causal factor in the pathogenesis of ischemic heart diseases [48]. There is an observed association between aortic stiffness and CAC [49]. The stiff arterial wall may be subjected to greater shear and intraluminal stresses as the result of increased pulsatile pressure, inducing vessel wall damage and endothelial cell dysfunction which are the crucial steps of coronary atherosclerosis [50].

There are several limitations in our study. First, the single-center study design limits the generalizability of our results. Second, as mentioned above we only included laboratory parameters and AACS at the baseline of the study. The lack of serial assessments leads to inevitable confounders. The presence of the longitudinal changes in the time-dependent variables may provide more solid information.

\section{Conclusions}

In summary, the present study implies the important role of AACS measured by lateral lumbar X-ray to independently predict all-cause mortality and MACCEs in a large Chinese PD cohort. This cheap and easy method facilitates the evaluation of vascular calcification in patients undergoing PD and the stratification of the risk of cardiovascular and cerebrovascular disease.

\section{Abbreviations}

CVD: Cardiovascular disease; AACS: Abdominal aortic calcification score: MACCE: Major adverse cardiac and cerebrovascular events; PD: Peritoneal dialysis; HD: Hemodialysis; CKD: Chronic kidney disease; ESRD: End-stage renal disease; hs-CRP: high-sensitivity $C$ reaction protein; iPTH: intact parathyroid hormone; AKP: Alkaline phosphatase; Kt/N: Total weekly urea clearance; CT: Computed tomography; ACS: Acute coronary syndrome; PCI: Percutaneous coronary intervention; CABG: Coronary artery bypass grafting; SD: Standard deviation; IQR: Interquartile range; PWV: Pulse wave velocity

\section{Acknowledgments}

We thank all of the doctors at the Nephrology Department of Renji Hospital in Shanghai, China for their work.

\section{Authors' contributions}

$\mathrm{MD}$ and $\mathrm{YH}$ contribute equally to the manuscript. MD and $\mathrm{YH}$ participated in the design of the study and performed the statistical analysis. $Y X$ and $Y Z$ participated in clinical data collection. NZ guided and supported this study. WF conceived of the study, and participated in its design and coordination and helped to draft the manuscript. All authors read and approved the final manuscript.

\section{Funding}

This work was supported by the National Nature Science Foundation Grant of China $(81370864,81670691)$ and Shanghai Municipal Education Commission Gaofeng Clinical Medicine Grant (20152211).

\section{Availability of data and materials}

The datasets analyzed during the current study are available from the corresponding author on reasonable request. 


\section{Ethics approval and consent to participate}

All procedures performed in studies were in accordance with the ethical standards of Renji Hospital on human experimentation and with the Helsinki Declaration of 1975, as revised in 2000. Written informed consent was obtained from all patients before enrollment. This article does not contain any experiments with animals performed by any of the authors. Informed consent was obtained from all patients for being included in the study.

\section{Consent for publication}

Not applicable.

\section{Competing interests}

The authors declare that they have no competing interests.

\section{Received: 24 October 2019 Accepted: 21 April 2020}

\section{Published online: 30 April 2020}

\section{References}

1. Goodman WG, London G, Amann K, Block GA, Giachelli C, Hruska KA, Ketteler M, Levin A, Massy Z, McCarron DA, et al. Vascular calcification in chronic kidney disease. Am J Kidney Dis. 2004;43(3):572-9.

2. Blacher J, Guerin AP, Pannier B, Marchais SJ, London GM. Arterial calcifications, arterial stiffness, and cardiovascular risk in end-stage renal disease. Hypertension. 2001;38(4):938-42.

3. Schlieper G, Schurgers L, Brandenburg V, Reutelingsperger C, Floege J. Vascular calcification in chronic kidney disease: an update. Nephrol Dial Transplant. 2016;31(1):31-9

4. Yao Z, Wang C, Zhang Q, Ma S, Gui B, Duan C. Prevalence of abdominal artery calcification in dialysis patients with end-stage renal disease: a systematic review and meta-analysis. Int Urol Nephrol. 2017:49(11):2061-9.

5. Baum JKCC, Joseph L. Intramammary arterial CalcificationsAssociated with diabetes. Radiology. 1980;136:61-2.

6. Kauppila LI, Polak JF, Cupples LA, Hannan MT, Kiel DP, Wilson PW. New indices to classify location, severity and progression of calcific lesions in the abdominal aorta: a 25-year follow-up study. Atherosclerosis. 1997;132(2): 245-50.

7. Agatston AS, Janowitz WR, Hildner FJ, Zusmer NR, Viamonte M, Detrano R. Quantification of coronary artery calcium using ultrafast computed tomography. J Am Coll Cardiol. 1990;15(4):827-32.

8. Isakova T, Nickolas TL, Denburg M, Yarlagadda S, Weiner DE, Gutierrez OM, Bansal V, Rosas SE, Nigwekar S, Yee J, et al. KDOQI US commentary on the 2017 KDIGO clinical practice guideline update for the diagnosis, evaluation, prevention, and treatment of chronic kidney disease-mineral and bone disorder (CKD-MBD). Am J Kidney Dis. 2017:70(6):737-51.

9. Verbeke F, Van Biesen W, Honkanen E, Wikstrom B, Jensen PB, Krzesinski JM, Rasmussen M, Vanholder R, Rensma PL, Investigators CS. Prognostic value of aortic stiffness and calcification for cardiovascular events and mortality in dialysis patients: outcome of the calcification outcome in renal disease (CORD) study. Clin J Am Soc Nephrol. 2011;6(1):153-9.

10. Okuno S, Ishimura E, Kitatani K, Fujino Y, Kohno K, Maeno Y, Maekawa K, Yamakawa T, Imanishi Y, Inaba M, et al. Presence of abdominal aortic calcification is significantly associated with all-cause and cardiovascular mortality in maintenance hemodialysis patients. Am J Kidney Dis. 2007:49(3): $417-25$

11. Nolph KD, Moore HL, Twardowski ZJ, Khanna R, Prowant B, Meyer M, Ponferrada L. Cross-sectional assessment of weekly urea and creatinine clearances in patients on continuous ambulatory peritoneal dialysis. ASAIO J. 1992;38(3):M139-42.

12. van Olden RW, Krediet RT, Struijk DG, Arisz L. Measurement of residual renal function in patients treated with continuous ambulatory peritoneal dialysis. J Am Soc Nephrol. 1996;7(5):745-50.

13. Noordzij M, Leffondré K, van Stralen KJ, Zoccali C, Dekker FW, Jager KJ. When do we need competing risks methods for survival analysis in nephrology? Nephrol Dial Transplant. 2013;28(11):2670-7.

14. Lumlertgul D, Kantachuvesiri S, Apichaiyingyurd S, Treamtrakanpon W, Rattanasompattikul M, Gojaseni P, Thanakitcharu P, Trakarnvanich T, Poonvivatchaikarn $\mathrm{U}$, Vareesangthip $\mathrm{K}$, et al. Prevalence of and predictive factor for abdominal aortic calcification in Thai chronic kidney disease patients. Ther Apher Dial. 2017;21(6):611-9.

15. Liu ZH, Yu XQ, Yang JW, Jiang AL, Liu BC, Xing CY, Lou JZ, Wang M, Cheng $\mathrm{H}, \mathrm{Liu} \mathrm{J}$, et al. Prevalence and risk factors for vascular calcification in Chinese patients receiving dialysis: baseline results from a prospective cohort study. Curr Med Res Opin. 2018:34(8):1491-500.

16. Honkanen E, Kauppila L, Wikstrom B, Rensma PL, Krzesinski JM, Aasarod K, Verbeke $F$, Jensen PB, Mattelaer P. Volck B. Abdominal aortic calcification in dialysis patients: results of the CORD study. Nephrol Dial Transplant. 2008; 23(12):4009-15.

17. Jansz $T$, Verhaar MC, London $G M$, van Jaarsveld $B C$. Is progression of coronary artery calcification influenced by modality of renal replacement therapy? A systematic review. Clin Kidney J. 2018;11(3):353-61.

18. Tesauro M, Mauriello A, Rovella V, Annicchiarico-Petruzzelli M, Cardillo C, Melino G, Di Daniele N. Arterial ageing: from endothelial dysfunction to vascular calcification. J Intern Med. 2017;281(5):471-82

19. Toussaint ND, Pedagogos E, Lau KK, Heinze S, Becker GJ, Beavis J, Polkinghorne KR, Damasiewicz MJ, Kerr PG. Lateral lumbar X-ray assessment of abdominal aortic calcification in Australian haemodialysis patients. Nephrology (Carlton). 2011;16(4):389-95.

20. Stary HC, Chandler AB, Dinsmore RE, Fuster V, Glagov S, Insull W Jr, Rosenfeld ME, Schwartz CJ, Wagner WD, Wissler RW. A definition of advanced types of atherosclerotic lesions and a histological classification of atherosclerosis. A report from the committee on vascular lesions of the council on arteriosclerosis, American Heart Association. Circulation. 1995; 92(5):1355-74

21. Cozzolino M, Mazzaferro S, Pugliese F, Brancaccio D. Vascular calcification and uremia: what do we know? Am J Nephrol. 2008;28(2):339-46.

22. Shroff RC, McNair R, Figg N, Skepper JN, Schurgers L, Gupta A, Hiorns M, Donald AE, Deanfield J, Rees $L$, et al. Dialysis accelerates medial vascular calcification in part by triggering smooth muscle cell apoptosis. Circulation. 2008:118(17):1748-57.

23. Avila M, Mora C, Prado MDC, Zavala M, Paniagua R. Osteoprotegerin is the strongest predictor for progression of arterial calcification in peritoneal Dialysis patients. Am J Nephrol. 2017:46(1):39-46

24. Johnson RC, Leopold JA, Loscalzo J. Vascular calcification: pathobiological mechanisms and clinical implications. Circ Res. 2006;99(10):1044-59.

25. Laakso M, Kuusisto J. Insulin resistance and hyperglycaemia in cardiovascular disease development. Nat Rev Endocrinol. 2014:10(5):293-302.

26. Block GA. Prevalence and clinical consequences of elevated Ca $\times$ P product in hemodialysis patients. Clin Nephrol. 2000;54(4):318-24.

27. Huang JW, Lien YC, Yang CY, Liu KL, Wu CF, Yen CJ, Wu CK, Lee JK, Ho SR Wu HY, et al. Osteoprotegerin, inflammation and dyslipidemia are associated with abdominal aortic calcification in non-diabetic patients on peritoneal dialysis. Nutr Metab Cardiovasc Dis. 2014;24(3):236-42.

28. Disthabanchong $\mathrm{S}$, Boongird $\mathrm{S}$. Role of different imaging modalities of vascular calcification in predicting outcomes in chronic kidney disease. World J Nephrol. 2017;6(3):100-10.

29. Wilson PW, Kauppila LI, O'Donnell CJ, Kiel DP, Hannan M, Polak JM, Cupples LA. Abdominal aortic calcific deposits are an important predictor of vascular morbidity and mortality. Circulation. 2001;103(11):1529-34.

30. Walsh CR, Cupples LA, Levy D, Kiel DP, Hannan M, Wilson PWF, O'Donnell CJ. Abdominal aortic calcific deposits are associated with increased risk for congestive heart failure: the Framingham heart study. Am Heart J. 2002; 144(4):733-9,

31. Bellasi A, Ferramosca E, Muntner P, Ratti C, Wildman RP, Block GA, Raggi P. Correlation of simple imaging tests and coronary artery calcium measured by computed tomography in hemodialysis patients. Kidney Int. 2006;70(9): 1623-8.

32. Chen HC, Chou CY, Lin HJ, Huang CC, Chang CT. Abdominal aortic calcification score predicts the occurrence of coronary artery disease in middleaged peritoneal dialysis patients. Nephrology (Carlton). 2019;24(3): $336-40$.

33. Martino F, Di Loreto P, Giacomini D, Kaushik M, Rodighiero MP, Crepaldi C, Ronco C. Abdominal aortic calcification is an independent predictor of cardiovascular events in peritoneal dialysis patients. Ther Apher Dial. 2013; 17(4):448-53.

34. Mäkelä S, Asola M, Hadimeri H, Heaf J, Heiro M, Kauppila L, Ljungman S , Ots-Rosenberg M, Povlsen JV, Rogland B, et al. Abdominal aortic calcifications predict survival in peritoneal Dialysis patients. Perit Dial Int. 2018:38(5):366-73.

35. Chen NC, Hsu CY, Chen CL. The strategy to prevent and regress the vascular calcification in Dialysis patients. Biomed Res Int. 2017:2017:9035193. 
36. Sánchez C, López-Barea F, Sánchez-Cabezudo J, Bajo A, Mate A, Martínez E, Selgas R. European Dialysis, Association TA-ER: Low vs standard calcium dialysate in peritoneal dialysis: differences in treatment, biochemistry and bone histomorphometry. A randomized multicentre study. Nephrol Dial Transplant. 2004;19(6):1587-93.

37. Cao X-Y, Zhou J-H, Cai G-Y, Ding R, Tang L, Wu D, Wei R-B, Chen X-M. Medicine e: Long term effects on mineral and bone metabolism by low versus standard calcium dialysate in peritoneal dialysis: a meta-analysis. Int J Clin Exp Med. 2015;8(2):2031.

38. Jamal SA, Vandermeer B, Raggi P, Mendelssohn DC, Chatterley T, Dorgan M, Lok CE, Fitchett D, Tsuyuki RT. Effect of calcium-based versus non-calciumbased phosphate binders on mortality in patients with chronic kidney disease: an updated systematic review and meta-analysis. Lancet. 2013; 382(9900):1268-77.

39. Suzuki H, Inoue T, Watanabe Y, Kikuta T, Sato T, Tsuda M, Uchida K. Does cinacalcet $\mathrm{HCl}$, an oral calcimimetic agent for the treatment of secondary hyperparathyroidism, improve arterial stiffness in patients on continuous ambulatory peritoneal dialysis? Adv Perit Dial. 2011;27:134-9.

40. Chow KM, Szeto CC, Kwan BC, Cheng PM, Pang WF, Leung CB, Li PK. Effect of cinacalcet treatment on vascular arterial stiffness among peritoneal dialysis patients with secondary hyperparathyroidism. Nephrology (Carlton). 2014:19(6):339-44.

41. Sigrist M, Bungay P, Taal MW, Mclntyre CW. Vascular calcification and cardiovascular function in chronic kidney disease. Nephrol Dial Transplant. 2006;21(3):707-14.

42. Raggi P, Bellasi A, Ferramosca E, Islam T, Muntner P, Block GA. Association of pulse wave velocity with vascular and valvular calcification in hemodialysis patients. Kidney Int. 2007;71(8):802-7.

43. Nichols WW ORM: Vascular impedance. In: McDonald's Blood Flow in Arteries: Theoretical Experimental and Clinical Principles. 5th edn. Edited by Arnold H. London: Oxford University Press 2005. pp. 137-148, 216-231, 233-267.

44. Klassen PS, Lowrie EG, Reddan DN, DeLong ER, Coladonato JA, Szczech LA, Lazarus JM, Owen WF Jr. Association between pulse pressure and mortality in patients undergoing maintenance hemodialysis. Jama. 2002;287(12): 1548-55.

45. Yildiz A, Memisoglu E, Oflaz H, Yazici H, Pusuroglu H, Akkaya V, Erzengin F, Tepe $\mathrm{S}$. Atherosclerosis and vascular calcification are independent predictors of left ventricular hypertrophy in chronic haemodialysis patients. Nephrol Dial Transplant. 2005;20(4):760-7.

46. Zoccali C, Benedetto FA, Mallamaci F, Tripepi G, Giacone G, Stancanelli B, Cataliotti A, Malatino LS. Left ventricular mass monitoring in the follow-up of dialysis patients: prognostic value of left ventricular hypertrophy progression. Kidney Int. 2004;65(4):1492-8.

47. London GM, Marchais SJ, Guerin AP. Arterial stiffness and function in endstage renal disease. Adv Chronic Kidney Dis. 2004;11(2):202-9.

48. Chen J, Budoff MJ, Reilly MP, Yang W, Rosas SE, Rahman M, Zhang X, Roy JA, Lustigova E, Nessel L, et al. Coronary artery calcification and risk of cardiovascular disease and death among patients with chronic kidney disease. JAMA Cardiol. 2017:2(6):635-43.

49. van Popele NM, Mattace-Raso FU, Vliegenthart R, Grobbee DE, Asmar R, van der Kuip DA, Hofman A, de Feijter PJ, Oudkerk M, Witteman JC. Aortic stiffness is associated with atherosclerosis of the coronary arteries in older adults: the Rotterdam study. J Hypertens. 2006;24(12):2371-6.

50. Demer LL. Effect of calcification on in vivo mechanical response of rabbit arteries to balloon dilation. Circulation. 1991;83(6):2083-93.

\section{Publisher's Note}

Springer Nature remains neutral with regard to jurisdictional claims in published maps and institutional affiliations.

Ready to submit your research? Choose BMC and benefit from:

- fast, convenient online submission

- thorough peer review by experienced researchers in your field

- rapid publication on acceptance

- support for research data, including large and complex data types

- gold Open Access which fosters wider collaboration and increased citations

- maximum visibility for your research: over $100 \mathrm{M}$ website views per year

At BMC, research is always in progress.

Learn more biomedcentral.com/submissions 